\title{
Thermal Effectiveness Characteristics of Low Approach Indirect Evaporative Cooling Systems in Buildings
}

\author{
Ben Costelloe \\ Technological University Dublin, ben.costelloe@tudublin.ie \\ Donal Finn \\ University College Dublin, donal.finn@ucd.ie
}

Follow this and additional works at: https://arrow.tudublin.ie/engschcivart

Part of the Civil and Environmental Engineering Commons, Education Commons, Environmental Design Commons, Mechanical Engineering Commons, Physical Sciences and Mathematics Commons, Technology and Innovation Commons, and the Thermodynamics Commons

\section{Recommended Citation}

Costelloe, B., Finn, D.: Thermal Effectiveness Characteristics of Low Approach Indirect Evaporative Cooling Systems in Buildings. Energy and Buildings, Volume 39, Issue 12, Pages 1235-1243, December 2007. doi:10.1016/j.enbuild.2007.01.003

This Article is brought to you for free and open access by the School of Civil and Structural Engineering at ARROW@TU Dublin. It has been accepted for inclusion in Articles by an authorized administrator of ARROW@TU

Dublin. For more information, please contact

arrow.admin@tudublin.ie, aisling.coyne@tudublin.ie, gerard.connolly@tudublin.ie.

Funder: CIBSE, Enterprise Ireland, DIT Seed Fund

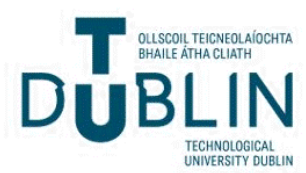




\title{
Thermal effectiveness characteristics of low approach indirect evaporative cooling systems in buildings
}

\author{
B. Costelloe ${ }^{\text {a,* }}$, D. Finn ${ }^{\text {b }}$ \\ ${ }^{a}$ Department of Building Services Engineering, Dublin Institute of Technology, Bolton Street, Dublin 1, Ireland \\ ${ }^{\mathrm{b}}$ School of Electrical, Electronic and Mechanical Engineering, University College Dublin, Ireland
}

Received 21 December 2006; accepted 4 January 2007

\begin{abstract}
Meteorological enthalpy analysis of temperate and maritime climates above latitude $45^{\circ} \mathrm{N}$ suggests that the water-side evaporative cooling technique has considerable unrealised potential with contemporary "high temperature" building cooling systems—such as chilled ceilings and displacement ventilation. As low approach conditions are the key to exploiting the cooling potential of the ambient air, thermal performance at such conditions needs to be investigated. To address the research issues, an industrial scale test rig, based on a low approach open cooling tower and plate heat exchanger and designed to maximise evaporative cooling potential, has been constructed.

The thermal effectiveness of such systems (as a measure of the degree to which the system has succeeded in exploiting the cooling potential of the ambient air) is a key parameter. This paper presents the results of experimental research into the thermal effectiveness of a water-side, open, indirect evaporative cooling test rig, designed to achieve low (1-4 K) approach conditions in the temperate maritime climate of northern Europe. The sensitivity of the thermal effectiveness to a series of key operating variables is investigated. High thermal effectiveness of up to 0.76 was found with both cooling tower air-flow rate and secondary water-flow rate having a strong impact. Primary water-flow rate however, has a weak impact on thermal effectiveness but a major impact on energy performance-indicating scope for a considerable improvement in energy performance at the expense of a minor reduction in thermal effectiveness. A proposed energy efficient control strategy for this form of cooling water generation is proposed and supported by an analysis of the measured results.
\end{abstract}

(C) 2007 Elsevier B.V. All rights reserved.

Keywords: Free cooling; Low energy cooling; Evaporative cooling; Cooling towers; Chilled ceilings; Displacement ventilation; Thermal effectiveness

\section{Introduction and background}

Traditionally interest in evaporative cooling, as an effective cooling technique for buildings, was focused on hot dry latitudes [1], where it was seen as being mainly applicable. Up to quite recently this focus has persisted [2]. Recent work however on air-side [3], and water-side [4] evaporative cooling, has demonstrated the considerable potential of the technique in temperate and maritime European regions above $45^{\circ} \mathrm{N}$ latitude.

Abbreviations: AST, adiabatic saturation temperature; WBT, psychrometric wet bulb temperature; DBT, dry bulb temperature; PAT, primary approach temperature; SAT, secondary approach temperature; PTE, primary thermal effectiveness; STE, secondary thermal effectiveness; PHE, plate heat exchanger; ASWR, air to secondary water-flow rate ratio; SWFR, secondary water-flow rate; $\mathrm{COP}$, coefficient of energy performance

* Corresponding author. Tel.: +3531 4023826; fax: +3531 4926326

E-mail address: ben.costelloe@dit.ie (B. Costelloe).
While the water-side evaporative cooling technique can be exploited with any water based building cooling system, the technique is particularly advantageous when used in conjunction with a chilled ceiling system and displacement ventilation, due to the higher cooling water temperatures $\left(14-18{ }^{\circ} \mathrm{C}\right)$ which are employed and hence the higher cooling water annual availability levels which result.

Fig. 1 shows a simplified schematic of a water-side indirect evaporative cooling system, with the key operating parameters indicated. The natural governing parameter is the adiabatic saturation temperature (AST), approximated by the psychrometric wet bulb temperature (WBT) of the ambient air. An important performance parameter is the primary approach temperature (PAT), defined as $T_{\mathrm{ps}}-T_{\mathrm{as}}$. This parameter is complicated by the requirement, in contemporary applications, to separate the tower water circuit from the building cooling circuit with a heat exchanger. Hence the significant performance parameter becomes the secondary approach temperature 


$\begin{array}{ll}\text { Nomenclature } \\ F_{\mathrm{a}} & \text { proportional change in approach condition } \\ F_{\mathrm{r}} & \text { proportional change in range condition } \\ G & \text { air-flow rate in the tower }(\mathrm{kg} / \mathrm{s}) \\ G^{\prime} & \text { air-flow rate flux in the tower }\left(\mathrm{kg} / \mathrm{s} \mathrm{m}^{2}\right) \\ h_{\mathrm{c}} & \text { convection heat-transfer coefficient }\left(\mathrm{W} / \mathrm{m}^{2} \mathrm{~K}\right) \\ k & \text { thermal conductivity }(\mathrm{W} / \mathrm{m} \mathrm{K}) \\ L & \text { primary water-flow rate in tower }(\mathrm{kg} / \mathrm{s}) \\ L^{\prime} & \text { primary water-flow rate flux in tower }\left(\mathrm{kg} / \mathrm{s} \mathrm{m}^{2}\right) \\ Q & \text { cooling load imposed }(\mathrm{kW}) \\ T_{\mathrm{as}} & \text { ambient adiabatic saturation temperature }(\mathrm{AST}) \\ & \left.\text { ( }{ }^{\circ} \mathrm{C}\right) \\ T_{\mathrm{pa}} & \text { primary approach temperature }(\mathrm{PAT})(\mathrm{K}) \\ T_{\mathrm{pr}} & \text { primary loop return temperature }\left({ }^{\circ} \mathrm{C}\right) \\ T_{\mathrm{ps}} & \text { primary loop supply temperature }\left({ }^{\circ} \mathrm{C}\right) \\ T_{\mathrm{sa}} & \text { secondary approach temperature }(\mathrm{SAT})(\mathrm{K}) \\ T_{\mathrm{sr}} & \text { secondary loop return temperature }\left({ }^{\circ} \mathrm{C}\right) \\ T_{\mathrm{ss}} & \text { secondary loop supply temperature }\left({ }^{\circ} \mathrm{C}\right) \\ V & \text { average velocity of water between plates in heat } \\ & \text { exchanger }(\mathrm{m} / \mathrm{s}) \\ z & \text { characteristic dimension between plates of heat } \\ & \text { exchanger (m) } \\ \text { Greek } & \text { letters } \\ \eta_{\mathrm{tp}} & \text { primary thermal effectiveness } \\ \eta_{\mathrm{ts}} & \text { secondary thermal effectiveness } \\ v & \text { kinematic viscosity of water }\left(\mathrm{m}^{2} / \mathrm{s}\right) \\ \text { Subscripts } & \text { adiabatic saturation } \\ \text { as } & \text { primary approach } \\ \mathrm{pa} & \text { primary return } \\ \mathrm{pr} & \text { primary supply } \\ \mathrm{ps} & \text { secondary approach } \\ \mathrm{sa} & \text { secondary return } \\ \mathrm{sr} & \text { secondary supply } \\ \mathrm{ss} & \text { thermal primary } \\ \mathrm{tp} & \text { thermal secondary } \\ \mathrm{ts} & \\ & \end{array}$

(SAT), which is defined as $T_{\mathrm{ss}}-T_{\mathrm{as}}$. It has been shown that cooling water availability levels very heavily depend on the approach conditions achieved in European locations and that SATs as low as $3 \mathrm{~K}$ are technically feasible with contemporary cooling tower packing surface densities of $200 \mathrm{~m}^{2} / \mathrm{m}^{3}$ and low approach plate heat exchangers [5]. Hence, when chilled ceiling systems are used, with typical cooling water supply temperatures of $14-18{ }^{\circ} \mathrm{C}$ considerable levels of cooling water availability are possible in many European and some Middle Eastern cities, as indicated in Table 1. These cities have similar design WBTs (the variation range is $< \pm 1 \mathrm{~K}$ ), but have significantly different and in some cases widely different dry bulb temperatures (DBT) and locations.

There are two basic approaches to this form of indirect cooling system: (i) the closed (with integral heat exchanger) wet cooling tower and (ii) the open tower with external plate heat exchanger. Each arrangement has advantages in particular circumstances and locations [6]. The thermal performance of closed towers in this application has been the subject of a multifaceted research project (EcoCool) by an international research group in recent years [7-10]. While the thermal performance of the closed tower in this application, has, therefore, been the subject of much research there is a need to investigate the thermal performance of the alternative approach with an open tower and external plate heat exchanger.

In the application, considered in this research, the operating conditions are well outside those encountered in refrigeration condenser heat rejection, with range and approach conditions as low as $1-4 \mathrm{~K}$, cooling water temperatures of $14-18^{\circ} \mathrm{C}$ and ambient conditions of $<20^{\circ} \mathrm{C}$ AST and generally $<25^{\circ} \mathrm{C}$ DBT. In these conditions, the difference between the cooling tower water temperature and the cooling tower air temperature is small and consequentially there are much reduced levels of enthalpy difference, the key driving force in the tower. Hence the associated volumetric heat and mass transfer rates in summer are smaller with, crucially, resulting higher air and water-flow rates, per unit of load rejected.

\section{Methodology and approach}

This paper presents the results of experimental research into the thermal effectiveness of a water-side, open, indirect evaporative cooling test rig, designed to achieve low (1-4 K) approach conditions in the temperate maritime climate of northern Europe. To investigate the research issues an industrial scale experimental research facility has been developed at the Dublin Institute of Technology and is described in detail elsewhere [6]. The test rig consists of an open counter-flow cooling tower and counter-flow plate heat exchanger, both with enhanced heat-transfer areas for the purpose of minimizing the approach conditions. The tower has $195 \mathrm{~m}^{2}$ of wave-form packing with a surface density of $200 \mathrm{~m}^{2} / \mathrm{m}^{3}$, while the plate heat exchanger has a design overall heat-transfer coefficient of $4691 \mathrm{~W} / \mathrm{m}^{2} \mathrm{~K}$. The cooling tower has a high degree of inbuilt operating flexibility with an air and water-flow rate range of $0.8-2.8 \mathrm{~m}^{3} / \mathrm{s}$ and $0.8-2.4 \mathrm{~L} / \mathrm{s}$, respectively, giving a possible $L / G$ mass-flow rate ratio range of 0.25-3.0. The cooling tower fan motor is inverter controlled while the $24 \mathrm{~kW}$ electric cooling load heater is thyristor controlled. SATs as low as $2 \mathrm{~K}$ have been measured in the rig at an AST of $17^{\circ} \mathrm{C}$ and $20 \mathrm{~kW}$ heat rejected.

A suitable means of assessing the thermal performance of the process is the thermal effectiveness $\left(\eta_{t}\right)$. This is defined as the cooling achieved, expressed as a fraction of the maximum possible cooling which could have been achieved in the ambient conditions pertaining. For the secondary circuit this parameter is defined by Eq. (1); a similar equation defines the primary circuit. As this parameter involves both the approach and the range condition - the two key determinants of energy performance - it is also a suitable parameter from this point of view. In particular the secondary thermal effectiveness (STE) is an important parameter as it assesses the performance of the indirect system as a whole, as distinct from the performance of the tower. The STE is related to the SAT, with the STE rising as 


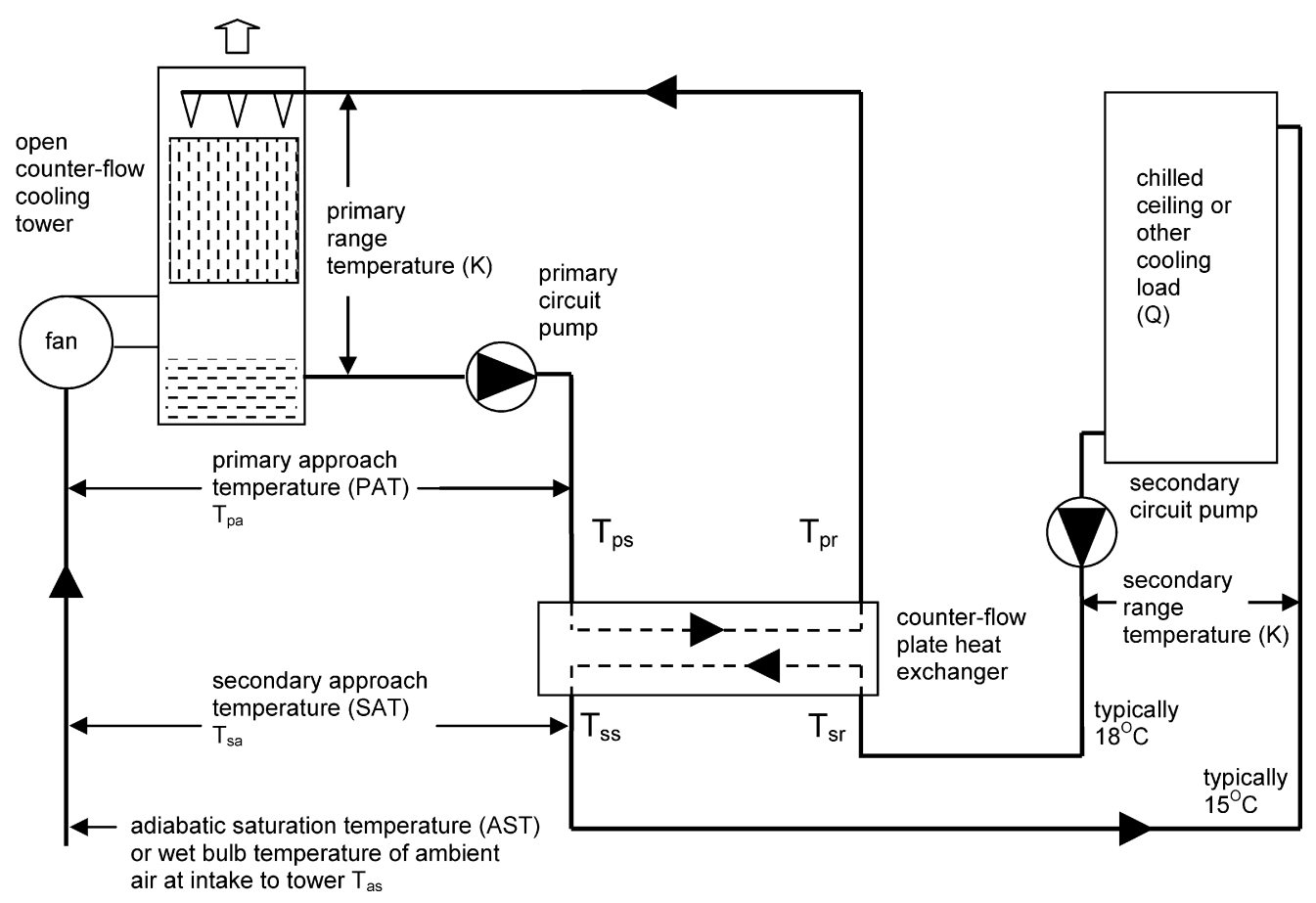

Fig. 1. Simplified schematic of a water-side indirect evaporative cooling system.

the SAT falls, at any given secondary range temperature. As such, therefore, it is also an important indicator of annual availability of cooling water generation potential.

The STE can be defined with reference to Fig. 1 in terms of the following equation:

$\eta_{\mathrm{ts}}=\frac{T_{\mathrm{sr}}-T_{\mathrm{ss}}}{T_{\mathrm{sr}}-T_{\mathrm{as}}}=\frac{T_{\mathrm{sr}}-T_{\mathrm{ss}}}{\left(T_{\mathrm{sr}}-T_{\mathrm{ss}}\right)+\left(T_{\mathrm{ss}}-T_{\mathrm{as}}\right)}$

which can be expressed qualitatively as

secondary range

$\overline{(\text { secondary range })+(\text { secondary approach })}$

For a given range condition (achieved by a fixed water-flow rate and a constant load) the effectiveness is a measure of the approach achieved. The effectiveness parameter is, therefore, a suitable yardstick against which the thermal behaviour of the heat dissipation system as a whole can be assessed.

Tests were conducted to investigate the impact of a range of operating variables on the thermal effectiveness achieved. These variables are:

- the cooling load imposed $(Q)$,

- the ambient AST,

- the primary circuit water-flow rate $(L)$,

- the secondary circuit water-flow rate,

- the cooling tower air-flow rate $(G)$.

For testing purposes the parameter being examined was varied while the other test rig variables were maintained constant. As there is no control over the ambient AST, a larger number of tests were conducted and those tests with near similar AST selected. Generally the criterion used is that the
AST should not vary within the selected test group by more than $\pm 0.9 \mathrm{~K}$.

While tests were conducted in the ambient WBT conditions pertaining in Dublin, these conditions, as shown in Table 1 are typical of many cities in north-west Europe, which are characterized by temperate semi-humid climates [3].

Table 1

European and Middle Eastern cities with similar summer design wet bulb temperatures (WBT) but different summer design dry bulb temperatures (DBT) (table in ascending order of the $1 \%$ summer design WBT [12])

\begin{tabular}{llll}
\hline City & $\begin{array}{l}1 \% \text { DBT } \\
\left({ }^{\circ} \mathrm{C}\right)\end{array}$ & $\begin{array}{l}1 \% \text { WBT } \\
\left({ }^{\circ} \mathrm{C}\right)\end{array}$ & $\begin{array}{l}2 \% \text { WBT } \\
\left({ }^{\circ} \mathrm{C}\right)\end{array}$ \\
\hline Dublin (Ireland) & 20.6 & 17.1 & 16.3 \\
Uppsala (Sweden) & 23.7 & 17.2 & 16.2 \\
Copenhagen (Denmark) & 23.2 & 17.4 & 16.5 \\
Oslo (Fornebu, Norway) & 24.8 & 17.4 & 16.5 \\
Helsinki (Finland) & 24.1 & 17.6 & 16.7 \\
Birmingham (UK) & 23.9 & 17.6 & 16.7 \\
Plymouth (UK) & 22.1 & 17.6 & 17.0 \\
Stockholm (Bromma, Sweden) & 24.2 & 17.7 & 16.7 \\
Al Jawf (Saudi Arabia) & 39.7 & 17.7 & 17.3 \\
Hof (Germany) & 25.0 & 17.8 & 16.8 \\
Ankara (Turkey) & 30.2 & 17.8 & 17.0 \\
Bristol (UK) & 24.5 & 18.2 & 17.3 \\
Khamis Mushayt (Saudi Arabia) & 30.6 & 18.2 & 17.6 \\
Gdansk (Poland) & 24.8 & 18.3 & 17.2 \\
Luxembourg & 26.1 & 18.5 & 17.6 \\
Brest (France) & 23.5 & 18.6 & 17.7 \\
Salamanca (Spain) & 32.0 & 18.6 & 17.8 \\
Prague (Czech Republic) & 26.8 & 18.7 & 17.8 \\
London (Heathrow, UK) & 25.7 & 18.7 & 17.8 \\
Hamburg (Germany) & 25.9 & 18.8 & 17.9 \\
Oostende (Belgium) & 23.0 & 18.8 & 18.0 \\
Munich (Germany) & 27.1 & 18.8 & 18.1 \\
Zurich (Switzerland) & 26.4 & 18.9 & 18.1 \\
\hline
\end{tabular}


Table 2

Variation in thermal effectiveness with load (flow rates: tower water flux $2.9 \mathrm{~kg}$ / $\mathrm{s} \mathrm{m}^{2}$, tower air flux $4.0 \mathrm{~kg} / \mathrm{s} \mathrm{m}^{2}$, secondary water $1.6 \mathrm{~kg} / \mathrm{s}$, AST $9.1^{\circ} \mathrm{C} \pm 0.7 \mathrm{~K}$ )

\begin{tabular}{llll}
\hline $\begin{array}{l}\text { Cooling load } \\
(\mathrm{kW})\end{array}$ & $\begin{array}{l}\text { Adiabatic } \\
\text { saturation } \\
\text { temperature }\left({ }^{\circ} \mathrm{C}\right)\end{array}$ & $\begin{array}{l}\text { Primary } \\
\text { thermal } \\
\text { effectiveness }\end{array}$ & $\begin{array}{l}\text { Secondary } \\
\text { thermal } \\
\text { effectiveness }\end{array}$ \\
\hline 24 & 8.9 & 0.52 & 0.50 \\
24 & 9.2 & 0.53 & 0.51 \\
20 & 8.5 & 0.56 & 0.52 \\
20 & 9.1 & 0.52 & 0.51 \\
15 & 8.7 & 0.56 & 0.52 \\
15 & 9.3 & 0.50 & 0.50 \\
15 & 9.8 & 0.50 & 0.50 \\
9 & 9.2 & 0.56 & 0.51
\end{tabular}

\section{Results and discussion of tests}

\subsection{Cooling load variation}

Tests were conducted to investigate the impact of load variation on the primary thermal effectiveness (PTE) and secondary thermal effectiveness (STE). In these tests as the imposed cooling load changes, the range temperatures change in direct proportion, as the cooling water-flow rates remain constant. Table 2 shows the results of these tests. The results clearly show that the thermal effectiveness is not affected by changes in load. This implies, as shown in Eq. (2), that the proportional change in the approach condition $\left(F_{\mathrm{a}}\right)$ must be approximately equal to the proportional change in the range condition $\left(F_{\mathrm{r}}\right)$, as the load is varied. As the change in the range condition is linear with load (at a constant water-flow rate) this implies a near linear correlation between the load and the approach temperature for the test rig:

$\eta_{\mathrm{tp}}=\frac{\left(T_{\mathrm{pr}}-T_{\mathrm{ps}}\right)\left(F_{\mathrm{r}}\right)}{\left(T_{\mathrm{pr}}-T_{\mathrm{ps}}\right)\left(F_{\mathrm{r}}\right)+\left(T_{\mathrm{ps}}-T_{\mathrm{as}}\right)\left(F_{\mathrm{a}}\right)}$

\subsection{Ambient AST variation}

To examine this aspect a large series of tests were conducted with ambient AST varying from 3 to $18{ }^{\circ} \mathrm{C}$. This is a typical annual range of such conditions in the temperate semi-humid climate of north-west Europe. For these tests the rig was maintained at maximum air and water-flow rate capacity so as to minimise the approach conditions and hence maximise the thermal effectiveness of the process. The results of these tests which are summarised in Fig. 2 indicate that both the PTE and STE are significantly affected by the ambient AST, with PTE being marginally more affected than STE. The STE increases at a rate of approximately $1.3 \%$ per degree rise in ambient AST across the $15 \mathrm{~K}$ range of the tests. This is comparable with and larger than the variation of $8 \%$ in $10 \mathrm{~K}$, in a different range of ambient conditions $\left(10-20{ }^{\circ} \mathrm{C}\right.$ WBT) reported for the closed tower [7] in warmer southern European conditions. These results demonstrate that effectiveness is inherently and significantly greater when ambient conditions are higher and hence when the external component of the building cooling

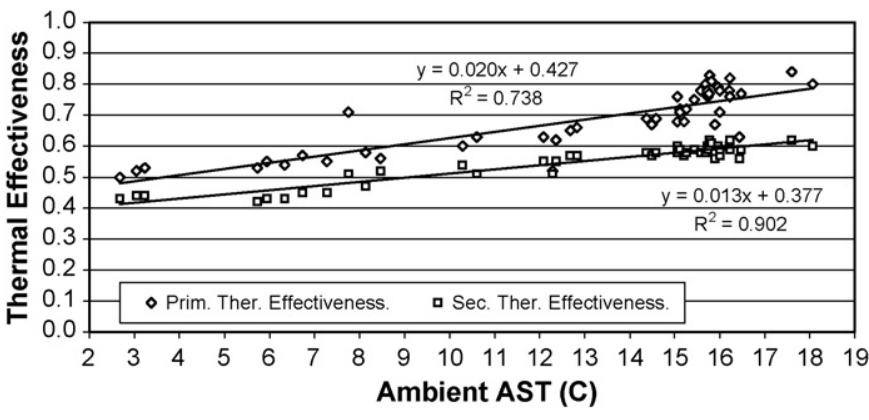

Fig. 2. Variation in thermal effectiveness with typical annual range of AST in Dublin (load $20 \mathrm{~kW}$, flow rates: tower water flux $2.9 \mathrm{~kg} / \mathrm{s} \mathrm{m}^{2}$, tower air flux $4.0 \mathrm{~kg} / \mathrm{s} \mathrm{m}^{2}$, secondary water $1.6 \mathrm{~kg} / \mathrm{s}$ ).

load is also higher, in Summer, i.e. when there is a greater demand for cooling. This strengthens the case for water-side evaporative cooling in buildings in temperate semi-humid climates. The results also indicate that the variation in the PTE was $2 \%$ per degree.

The secondary approach condition is composed of the sum of the primary approach and the plate heat exchanger approach. While the primary approach is directly affected by the ambient condition the approach of the plate heat exchanger $\left(T_{\mathrm{ss}}-T_{\mathrm{ps}}\right)$ is not. It is useful, therefore, to examine the variation in the approach conditions with ambient AST as this is the fundamental variation, which produces the variation in effectiveness, in accordance with Eq. (1). Fig. 3 shows the variation in the approach conditions with AST which under-lies the data in Fig. 2. As with Fig. 2, the AST range applies to a typical daytime annual range. The PAT varies from 0.5 to $2.0 \mathrm{~K}$ and the SAT from 2.0 to $4.0 \mathrm{~K}$. Both the primary and secondary approach have similar equations which indicate, that at the limit of the process, at an ambient AST of $0{ }^{\circ} \mathrm{C}$, the SAT is $4.6 \mathrm{~K}$ and the PAT $2.5 \mathrm{~K}$. At the mean AST of $10.5{ }^{\circ} \mathrm{C}$ the SAT is $3 \mathrm{~K}$ as shown. At this mean condition the PAT is $1.3 \mathrm{~K}$, and the PHE approach is $1.7 \mathrm{~K}$. The dependence of the approach condition on the AST is a key feature of the results. The fact that such low primary approach conditions can be achieved in high summer is an important factor in maximising availability at the time of highest load.

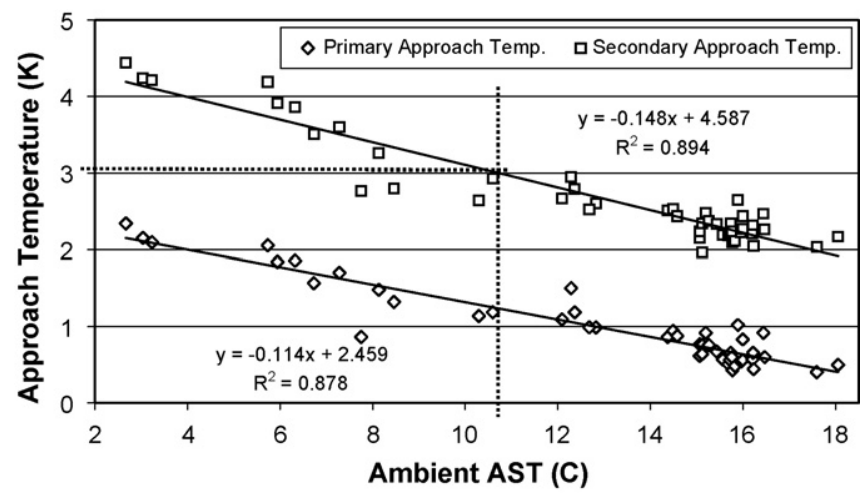

Fig. 3. Variation in primary and secondary approach temperature with annual range of AST in Dublin (load $20 \mathrm{~kW}$, flow rates: tower water flux $2.9 \mathrm{~kg} / \mathrm{s} \mathrm{m}^{2}$, tower air flux $4.0 \mathrm{~kg} / \mathrm{s} \mathrm{m}^{2}$, secondary water $1.6 \mathrm{~kg} / \mathrm{s}$ ). The mean AST of $10.5^{\circ} \mathrm{C}$ is shown with associated $3 \mathrm{~K} \mathrm{SAT}$. 
Table 3

Variation in convection heat-transfer coefficient of PHE with water temperature

\begin{tabular}{|c|c|c|c|c|}
\hline $\begin{array}{l}\text { Water } \\
\text { temperature }\left({ }^{\circ} \mathrm{C}\right)\end{array}$ & $\begin{array}{l}\text { Kinematic viscosity, } \\
v\left(\times 10^{-6} \mathrm{~m}^{2} / \mathrm{s}\right)\end{array}$ & $\begin{array}{l}\text { Prandtl } \\
\text { number }(P r)\end{array}$ & $\begin{array}{l}\text { Thermal conductivity, } \\
k(\mathrm{~W} / \mathrm{m} \mathrm{K})\end{array}$ & $\begin{array}{l}\text { Convection heat-transfer coefficient } \\
\text { based on Eq. (3), } h_{\mathrm{c}}\left(\mathrm{W} / \mathrm{m}^{2} \mathrm{~K}\right)\end{array}$ \\
\hline 10 & 1.306 & 9.43 & 0.5800 & $2295(V z)^{0.8} / z$ \\
\hline 20 & 1.004 & 7.00 & 0.5984 & $2646(V z)^{0.8} / z$ \\
\hline
\end{tabular}

Fig. 3 also indicates that the PHE approach is subject to a small variation over the ambient range as both regression lines are not quite parallel. Yet the PHE approach is not affected directly by ambient conditions. The PHE approach changes from $2.02 \mathrm{~K}$ at $3{ }^{\circ} \mathrm{C}$ to $1.52 \mathrm{~K}$ at $18{ }^{\circ} \mathrm{C}$, which is an average change of $1.65 \%$ per degree AST, across the $15 \mathrm{~K}$ range. As both-flow rates are constant, this is attributed to changes in the water temperature, with associated changes in the viscosity, thermal conductivity and Prandtl number, impacting on the heat-transfer coefficient. Table 3 shows the impact of a change in these parameters on the Nusselt number $(\mathrm{Nu})$ and on the convection heat-transfer coefficient $\left(h_{\mathrm{c}}\right)$ for the heat-transfer correlation [11] indicated in Eq. (3). This correlation is applicable to turbulent-flow over plates in a PHE. In this equation $z$ is the characteristic dimension and $V$ the water velocity between the plates of the heat exchanger:

$N u=0.037(\operatorname{Re})^{0.8}(\operatorname{Pr})^{0.33}$

therefore

$h_{\mathrm{c}}=(k / z) 0.037(\operatorname{Re})^{0.8}(\operatorname{Pr})^{0.33}$

or

$h_{\mathrm{c}}=(k / z) 0.037(V z / v)^{0.8}(P r)^{0.33}$

It is seen that the convection heat-transfer coefficient changes from $2295(V z)^{0.8} / z$ to $2646(V z)^{0.8} / z$ across the $10 \mathrm{~K}$ range due to the change in thermo-physical properties of water alone. This represents a change of $1.53 \%$ per degree. Hence the change in PHE approach is accounted for on the basis of the change in the physical properties of the water-mainly the change in kinematic viscosity and Prandtl number with temperature.

While Fig. 3 is based on the variation in thermal effectiveness with AST, it is possible also to examine the

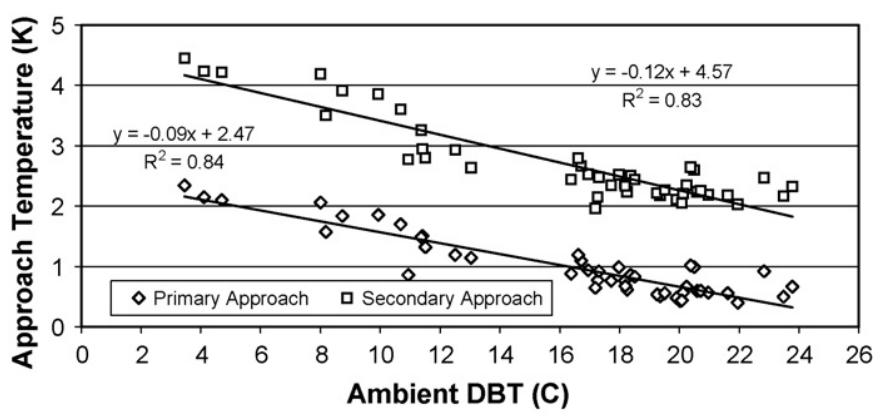

Fig. 4. Variation in primary and secondary approach temperature with annual range of dry bulb temperature (as the humidity ratio varies) in Dublin (load $20 \mathrm{~kW}$, flow rates: tower water flux $2.9 \mathrm{~kg} / \mathrm{s} \mathrm{m}^{2}$, tower air flux $4.0 \mathrm{~kg} / \mathrm{s} \mathrm{m}^{2}$, secondary water $1.6 \mathrm{~kg} / \mathrm{s}$ ). variation with dry bulb temperature (DBT) and humidity ratio, as these are the two components of the enthalpy and hence of the AST. The variation with DBT is measured and is available from the experimental data. The humidity ratio can be determined from the measured $\mathrm{RH}$ and measured DBT using the fundamental psychrometric equations involved [12]. Figs. 4 and 5 show the results of this work. While the general trend of the variation in approach condition with dry bulb temperature and humidity ratio is similar to that with AST and furthermore the variations reflect the ambient conditions present, the associated equations are different. The variation with humidity ratio is greater than that with the AST and the variation with DBT less than that with AST. As all these ambient conditions are typical of the daytime annual range of conditions in north-west Europe, the results suggest (see Figs. 4 and 5) that the variation in both approaches with humidity ratio is less linear than the variation with DBT and with AST, with a smaller variation above a humidity ratio of $6-7 \mathrm{~g} / \mathrm{kg}$.

This hypothesis is confirmed when a polynomial relationship is used for the variation with humidity ratio and the data fit is seen to be significantly better as shown in Fig. 6. This suggests that the DBT is a more important constituent of the AST than the humidity ratio from the perspective of reducing the approach and maximising availability. This in turn suggests that simply heating the incoming air to the tower in winter will reduce the primary approach temperature. However it will also raise the minimum temperature of the cooling water which can be generated. As a low approach is not normally required in winter however, such a strategy would also lower the energy performance of the process as fan power and heating energy would increase.

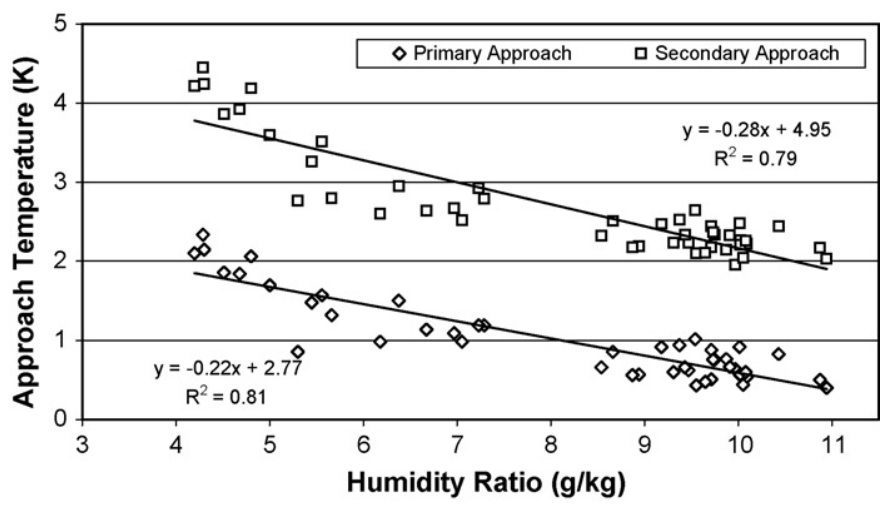

Fig. 5. Linear variation in primary and secondary approach temperature with annual range of humidity ratio (as the DBT varies) in Dublin (load $20 \mathrm{~kW}$, flow rates: tower water flux $2.9 \mathrm{~kg} / \mathrm{s} \mathrm{m}^{2}$, tower air flux $4.0 \mathrm{~kg} / \mathrm{s} \mathrm{m}^{2}$, secondary water $1.6 \mathrm{~kg} / \mathrm{s})$. 


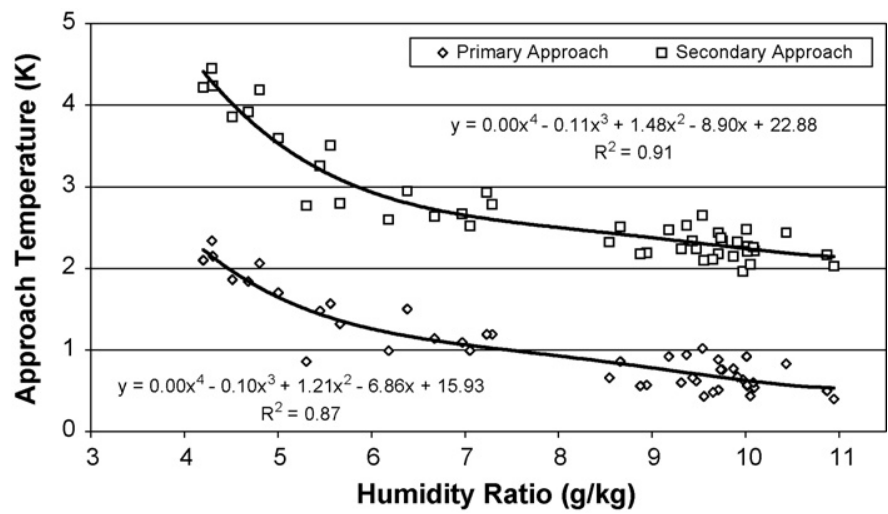

Fig. 6. Polynomial variation in primary and secondary approach temperature with annual range of humidity ratio (as the DBT varies) in Dublin (load $20 \mathrm{~kW}$, flow rates: tower water flux $2.9 \mathrm{~kg} / \mathrm{s} \mathrm{m}^{2}$, tower air flux $4.0 \mathrm{~kg} / \mathrm{s} \mathrm{m}^{2}$, secondary water $1.6 \mathrm{~kg} / \mathrm{s}$ ).

\subsection{Primary water-flow rate variation}

An extensive series of tests were conducted to investigate the dependence of the thermal effectiveness on the primary waterflow rate. These tests were conducted in four groups. For each group the air-flow rate and secondary water-flow rate was maintained constant while the primary water-flow rate was varied. For each group therefore there is a constant air to secondary water-flow rate ratio (ASWR). A summary of the results of these tests is shown in Fig. 7. The results show that the dependence of the secondary thermal effectiveness (STE) on the primary water-flow rate is weak. The relationship is strongest at the low ASWR of 0.8 and weakest at the high ASWR of 5.5, with dependence generally falling as the ASWR increases. In each case a power law relationship is indicated.

In this context it is interesting to examine conditions at a primary water-flow rate of $1.4 \mathrm{~kg} / \mathrm{s}$, which is equal to a flux of $1.7 \mathrm{~kg} / \mathrm{s} \mathrm{m}^{2}$. The energy performance or COP of the evaporative cooling test rig is a function of the air and primary water-flow rate and is described in detail elsewhere [5]. The results of an analysis of the COP of the test rig over the range of possible air and water-flow rate flux is shown in Fig. 8. This analysis indicates that approximately $1.7 \mathrm{~kg} / \mathrm{s} \mathrm{m}^{2}$ is the maximum-flow rate flux for which the energy performance of the evaporative cooling system is always above that of the best performing

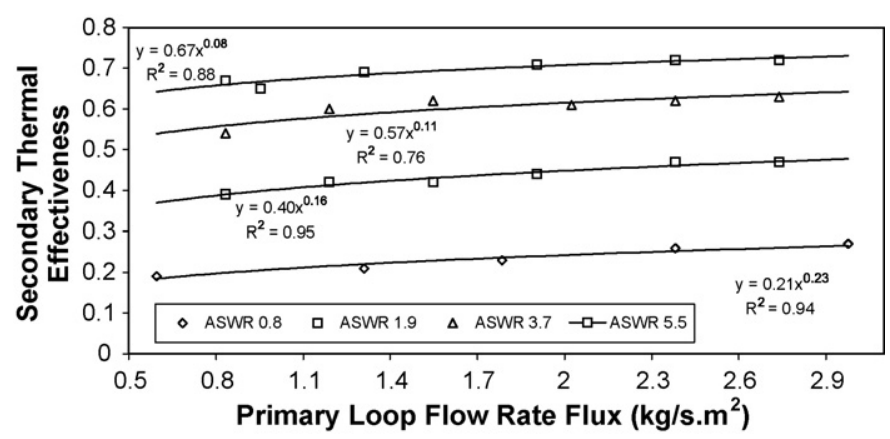

Fig. 7. Variation in secondary thermal effectiveness with primary loop flow rate for a series of four air to secondary water-flow rate ratios (ASWR). Load of $20 \mathrm{~kW}$ and AST $10.4{ }^{\circ} \mathrm{C} \pm 0.8 \mathrm{~K}$.

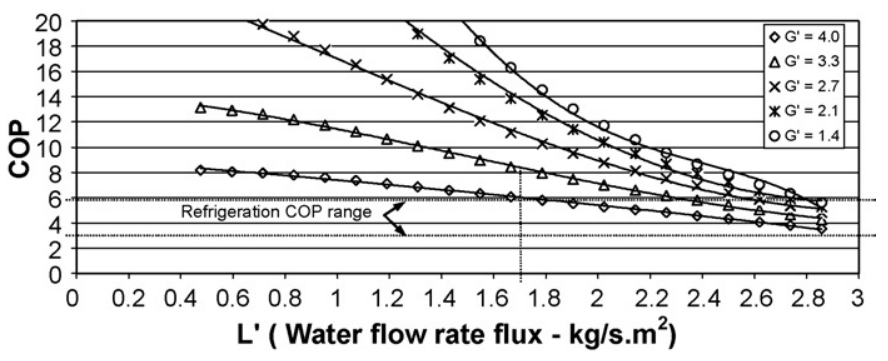

Fig. 8. Results of analysis of COP of the test rig as a function of the air-flow rate flux $\left(G^{\prime}, \mathrm{kg} / \mathrm{s} \mathrm{m}^{2}\right)$ and the water-flow rate flux $\left(L^{\prime}, \mathrm{kg} / \mathrm{s} \mathrm{m}^{2}\right)$. The range of total power input COP possible with vapour compression refrigeration (2.6-5.7) is also shown.

alternative vapour compression refrigeration performance. The valid comparison here is with the refrigeration system COP defined in terms of the total power input, as distinct from considering only the power input to the compressor. On this basis the likely refrigeration COP, ranging from small aircooled to large water-cooled equipment is $2.6-5.7[13,14]$.

With reference to Fig. 7 it is also evident that there is little increase in STE with increase in flux above a primary waterflow rate flux of $1.7 \mathrm{~kg} / \mathrm{s} \mathrm{m}^{2}$. This applies at all ASWR ratios but is particularly evident at the higher ratios with reference to the measured data points in Fig. 7 (for the closed tower this threshold was found to occur at a flux of approximately $1.4 \mathrm{~kg} /$ $\mathrm{s} \mathrm{m}^{2}$; [7]). Hence increasing the primary water flux above $1.7 \mathrm{~kg} / \mathrm{s} \mathrm{m}^{2}$ would seem to produce little improvement in the degree of exploitation of ambient cooling, which is achieved, but results in a significant decline in energy performance, whereby it approaches the performance, which can be achieved with the more efficient water cooled refrigeration systems.

It is suggested therefore, that at a flux of approximately $1.7 \mathrm{~kg} / \mathrm{s} \mathrm{m}^{2}$ the packing surface is fully wet and therefore further increases in flow rate serve only to increase the water film thickness, making little further impact on heat-transfer and hence on secondary thermal effectiveness. The flow rate flux of $1.7 \mathrm{~kg} / \mathrm{s} \mathrm{m}^{2}$ can, therefore, be seen as a key threshold level of the process from the point of view of the interrelationship between thermal and energy performance. Hence in the next series of tests, conducted to investigate the impact of the airflow rate and secondary water-flow rate, the primary water-flow rate flux was maintained at a constant flux of $1.7 \mathrm{~kg} / \mathrm{s} \mathrm{m}^{2}$.

\subsection{Air and secondary water-flow rate variation}

Fig. 9 shows the impact of air-flow rate on the STE for a series of four secondary water-flow rates (SWFR) — reducing in four equal steps of $25 \%$. It is seen that the impact of both of these variables is highly significant and can be contrasted with the relationship shown in Fig. 7. STE is greatly influenced by air-flow rate at all secondary water-flow rates, with effectiveness doubling, across the range of air-flow rates shown. This indicates also, with reference to Fig. 9, that the tower air-flow rate is a key determinant of the secondary approach temperature achieved and therefore of availability. Unlike the air-flow rate, the secondary water-flow rate is inversely 


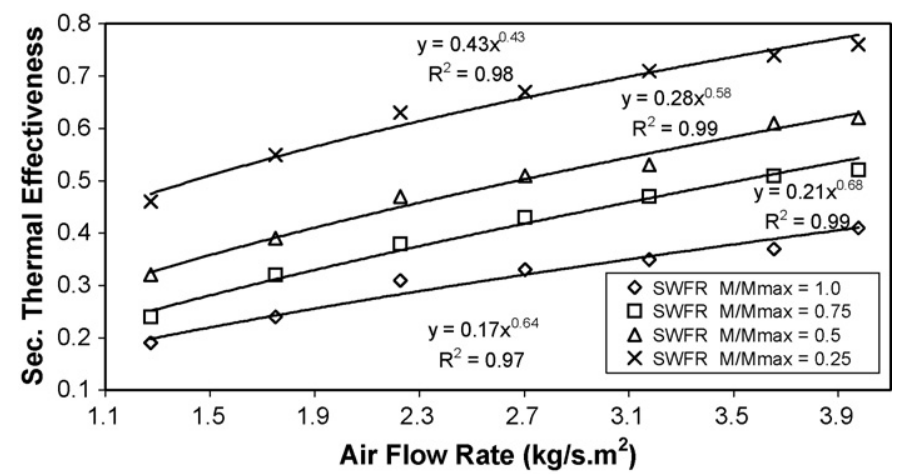

Fig. 9. Variation in secondary thermal effectiveness (STE) with air-flow rate flux for a series of four secondary water-flow rates (SWFR) at a constant load of $20 \mathrm{~kW}$, constant primary water-flow rate flux of $1.7 \mathrm{~kg} / \mathrm{s} \mathrm{m}^{2}$, AST of $8.4 \mathrm{C} \pm 0.9 \mathrm{~K}$. The SWFR is shown as a fraction of the maximum SWFR.

proportional to the effectiveness with lower-flow rates increasing the residence time in the heat exchanger and therefore reducing the approach. In an actual installation, however, the secondary flow rate is dictated by the load, the control strategy adopted and the design requirements of the building cooling system.

It is seen in Fig. 9 that the highest levels of STE (for the test rig 76\%) are obtained when the ambient AST is high and therefore the air-flow rate is high and the system secondary water-flow rate is low and therefore the cooling load is low. It is also seen from the results that approximately the same effectiveness is obtained when both the air-flow rate and secondary water-flow rate are maximum $(41 \%)$ and when both are minimum $(46 \%)$.

\subsection{Impact of thermal effectiveness on approach condition}

As the STE is a function only of the secondary range and secondary approach, the SAT can be expressed in terms of the STE and range condition. As the design range condition is determined by the system choice (typically $2 \mathrm{~K}$ for chilled beams, $3 \mathrm{~K}$ for chilled ceilings panels and 4 or $5 \mathrm{~K}$ for fan coil systems), the SAT can be determined as a function of the STE for a series of typical secondary range temperatures. Commencing with the definition of STE in the form of

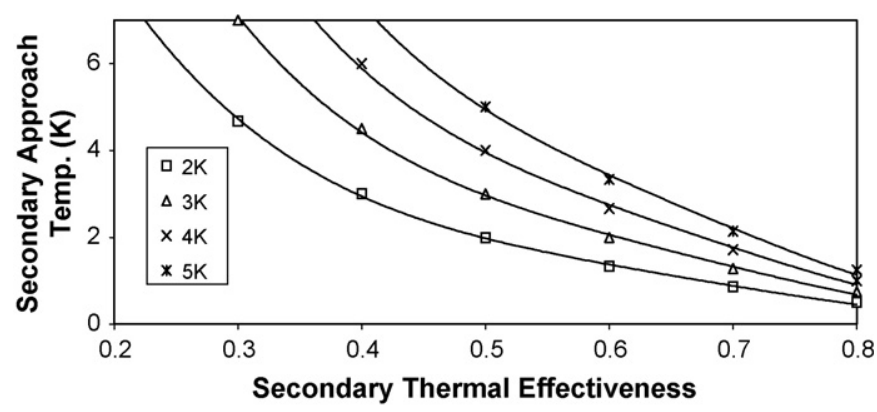

Fig. 10. Variation in secondary approach temperature with secondary thermal effectiveness for four typical range temperatures $(2-5 \mathrm{~K})$ commonly used in high temperature cooling.
Eq. (1) the SAT can be isolated as follows:

$T_{\mathrm{ss}}-T_{\mathrm{as}}=\frac{T_{\mathrm{sr}}-T_{\mathrm{ss}}}{\eta_{\mathrm{ts}}}-\frac{\eta_{\mathrm{ts}}\left(T_{\mathrm{sr}}-T_{\mathrm{ss}}\right)}{\eta_{\mathrm{ts}}}$

which can be expressed qualitatively as

$\mathrm{SAT}=\left(\frac{\text { secondary range }}{\mathrm{STE}}\right)-$ secondary range

For the four typical secondary range temperatures described above and using Eq. (4), the SAT can therefore be expressed in terms of the STE as shown in Fig. 10.

Fig. 10 confirms that for a low SAT to be achieved (of 2-4 K), a relatively low secondary range condition of less than $6 \mathrm{~K}$ is required. Fig. 9 indicates that the maximum STE achieved was $76 \%$ at full air-flow rate. This indicates that STEs in excess of approximately $75 \%$ are impractical and given the lowest SAT of $2 \mathrm{~K}$, recorded in Fig. 3, this implies that the maximum secondary range condition possible is $6 \mathrm{~K}$, if low approach conditions are to be achieved.

\section{Proposed energy efficient control strategy}

The relationship between STE and SAT as shown in Fig. 10 enables the operational thermal behaviour of the system to be examined during changes in the imposed internal load and external ambient condition, the two variables which are presented to the cooling system in all buildings. The cooling tower air-flow rate and secondary water-flow rate are the two variables which it is proposed are controlled in an actual chilled ceiling installation, which is operated by means of cooling water generated by evaporation. The proposed control arrangement is indicated in Fig. 11. With this arrangement, the room or zone cooling load is controlled by an energy efficient two-port valve arrangement, which results in a variable secondary water-flow rate at the heat exchanger. With a fixed secondary pump speed this will create pressure problems in the secondary system as the operating point on the pump characteristic varies in response to the varying-flow rate. Therefore it is suggested that the secondary pump be inverter controlled from a differential pressure sensor located as shown-effectively maintaining a constant differential pressure at a particular point in the system. Cooling tower air-flow rate can also be efficiently controlled by using a fan motor inverter to maintain a constant secondary supply water temperature, as ambient AST varies. To avoid the possibility of condensation occurring on the chilled ceiling, the set point of the secondary water supply temperature is reset upwards when the room air dew point comes within $2 \mathrm{~K}$ of the secondary supply water temperature. This situation is not likely to occur frequently [15]. Hence this proposed control arrangement provides an energy efficient form of control on both the tower and secondary side and will, therefore, provide an energy efficient control of the system as a whole. The alternative to this arrangement, on the secondary side is a three-port mixing valve in a diverting application which maintains a constant secondary 


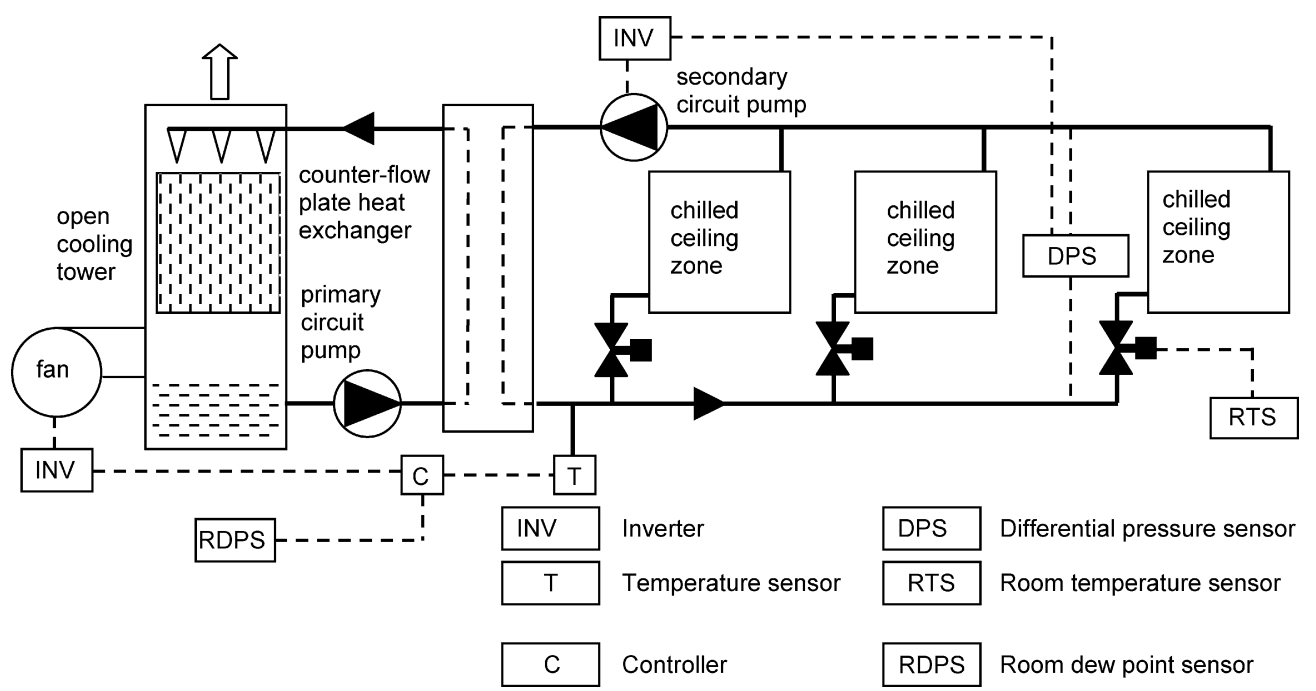

Fig. 11. Proposed energy efficient control strategy for the evaporative cooling system.

water-flow rate at all load conditions, which is clearly less energy efficient than the arrangement shown.

Building can be classified into those in which the cooling load is largely constant (mainly dominated internal loads) and those which experience significant variations in load. The building sensible cooling load however, must equal the product of the secondary mass-flow rate, the specific heat of water and the secondary range temperature. In a constant load building, the secondary water-flow rate and secondary range temperature therefore tend to be constant. In a variable load building in which a constant secondary water-flow rate control strategy is adopted, the range temperature tracks the load. However when a variable secondary water-flow rate control strategy is used the range temperature tends to remain approximately constant. These processes can now be examined with reference to Figs. 9 and 10.

In a constant load building the range temperature is constant, the STE falls as the ambient condition falls and the SAT expands as the air-flow rate is reduced in response to a falling ambient AST. This is seen clearly in Fig. 10 where the process of a constant range temperature under conditions of a falling STE and rising SAT are clearly seen. In a variable load building, with a constant secondary water-flow rate the range temperature tends to fall tracking the load while simultaneously the approach temperature rises in response to a falling ambient condition. This results in a sharply falling STE as seen in Fig. 10. However, where a variable secondary water-flow rate strategy is adopted, in this case, the range temperature tends to be constant and hence the fall in STE is less as the SAT expands. If either the imposed cooling load or the ambient condition falls then the tendency would be for the secondary water supply temperature to fall. However, this is maintained constant by reducing the cooling tower air-flow rate and hence energy performance is improved.

\section{Conclusions}

This paper outlines how the thermal effectiveness can be used as a measure of the degree to which the evaporative cooling system has succeeded in exploiting the cooling potential of the ambient air. The sensitivity of the thermal effectiveness to five key operating parameters has been measured and analysed. The following specific conclusions can be drawn:

- The test results indicate that thermal effectiveness is not affected by changes in load. A linear correlation, between the load and the approach temperature is inferred from the results.

- The results of the tests indicate that both the primary and secondary thermal effectiveness (and the corresponding approach conditions) are significantly affected by the ambient adiabatic saturation temperature, with primary effectiveness being marginally more affected than secondary effectiveness. The secondary effectiveness increases at a rate of approximately $1.3 \%$ per degree rise in ambient adiabatic saturation temperature across the $16 \mathrm{~K}$ range of the tests (a total increase, over the annual range, of $20 \%$ ). These results demonstrate that the effectiveness is inherently greater when the external component of the cooling load is higher in Summer, which significantly strengthens the case for waterside evaporative cooling in buildings. The results also suggest that the dry bulb temperature is a more important constituent of the adiabatic saturation temperature than the humidity ratio (particularly when the humidity ratio is above $6 \mathrm{~g} / \mathrm{kg}$ ) from the perspective of reducing the approach and maximising availability.

- The dependence of the secondary thermal effectiveness on the primary water-flow rate is weak. Above a primary waterflow rate flux of approximately $1.7 \mathrm{~kg} / \mathrm{s} \mathrm{m}^{2}$ there is little increase in secondary effectiveness. This implies that primary-flow rate can be reduced from a maximum, without a corresponding reduction in effectiveness and therefore in secondary approach and cooling water availability. Hence the energy performance of the process may be significantly improved in this way.

- The impact of air-flow rate and secondary water-flow rates on the secondary thermal effectiveness was examined. It is seen 
that the impact of both of these variables is highly significant and in contrast with the relationship for primary water-flow rate. Secondary thermal effectiveness is greatly influenced by air-flow rate at all secondary water-flow rates, with effectiveness increasing by approximately a factor of 2 , across the range of air-flow rates examined. This indicates that the tower air-flow rate rather than the primary water-flow rate is the key determinant of secondary approach and therefore of availability.

- It is clear that there is considerable scope for energy efficient control of the cooling tower fan and secondary pump, based on an inverter control technology, designed to exploit the thermal characteristic behaviour of the process during changes in imposed load and ambient condition. This control strategy is described and is supported by an analysis of the measured results.

\section{Acknowledgements}

This research programme has been supported financially by research grants from the CIBSE (Republic of Ireland Region), Enterprise Ireland, and the Dublin Institute of Technology (DIT). Equipment and services, donated by many private companies, is also gratefully acknowledged. The support of the Buildings Office, DIT and of the laboratory staff of the Department of Building Services Engineering, is likewise acknowledged.

\section{References}

[1] J.R. Watt, Evaporative Air Conditioning Handbook, Chapman and Hall, New York, 1986.
[2] J.G. Bom, R. Foster, E. Dijkstra, M. Tummers, Evaporative Air-Conditioning-Applications for Environmentally Friendly Cooling, World Bank Technical Paper No. 421, The World Bank, Washington, DC, 1999.

[3] IEA, in: N. Barnard, D. Jaunzens (Eds.), Low Energy Cooling-Annex 28 Subtask 2, International Energy Agency/Construction Research Communications, UK, 2001.

[4] B. Costelloe, D. Finn, Indirect evaporative cooling potential in air-water systems in temperate climates, Energy and Buildings 35 (2003) 573591.

[5] B. Costelloe, D. Finn, Experimental energy performance of open cooling towers used under low and variable approach conditions for indirect evaporative cooling in buildings, Building Services Engineering Research and Technology 24 (3) (2003) 163-177.

[6] B. Costelloe, D. Finn, The design and performance of an evaporative cooling test rig for a maritime climate, in: Proceedings of Joint CIBSE/ASHRAE Conference, Dublin, September, (2000), pp. 830845.

[7] J. Facao, A.C. Oliveira, Thermal behaviour of closed wet cooling towers for use with chilled ceilings, Applied Thermal Engineering 20 (2000) 1225-1236.

[8] A. Hasan, K. Siren, Theoretical and computational analysis of closed wet cooling towers and its application in cooling of buildings, Energy and Buildings 1398 (2001) 1-10.

[9] A. Hasan, K. Siren, Performance investigation of plain circular and oval tube evaporatively cooled heat exchangers, Applied Thermal Engineering 24 (2004) 777-790.

[10] G. Gan, S.B. Riffat, Application of CFD to closed wet cooling towers, Applied Thermal Engineering 21 (2001) 79-92.

[11] CIBSE, CIBSE Guide, Volume A, CIBSE, London, 1986.

[12] ASHRAE, ASHRAE Handbook: Fundamentals, ASHRAE, Atlanta, GA, 1997.

[13] Davis, Langdon, Everest, Chillers cost model, Building Services Journal (12) (1999) 13-14.

[14] L.D.D. Harvey, A Handbook on Low-Energy Buildings and DistrictEnergy Systems, Earthscan (James and James), London, 2006.

[15] D.J.G. Butler, Chilled Ceilings and Beams, Research Report RR5, CIBSE (with BRE), London, 1998. 